\title{
Towards a Classification of Left Common Iliac Vein Compression Based on Triplanar Phlebography
}

\author{
Raymond Englund \\ St. George Private Hospital, Kogarah, Australia \\ Email: renglund@ihug.com.au
}

How to cite this paper: Englund, R. (2017) Towards a Classification of Left Common Iliac Vein Compression Based on Triplanar Phlebography. Surgical Science, 8, 19-26. http://dx.doi.org/10.4236/ss.2017.81003

Received: September 22, 2016

Accepted: January 9, 2017

Published: January 12, 2017

Copyright $\odot 2017$ by author and Scientific Research Publishing Inc. This work is licensed under the Creative Commons Attribution International License (CC BY 4.0).

http://creativecommons.org/licenses/by/4.0/

\begin{abstract}
Introduction: There is currently no consistent classification of the extent of left common iliac vein compression syndromes such that clinicians working in the area have a common terminology. Hypothesis: To create a classification of left common iliac vein compression based on the end point of triplanar pelvic phlebogrpahy. Methods: Based on 61 consecutive patients found to have left common iliac vein compression on triplanar phlebography in the course of treatment of venous disease, clinical presentation and symptomatology were retrospectively used to create a classification of left common iliac vein compression. Treatment of left common iliac vein compression was also retrospectively correlated with staging. Results: The following classification was arrived at: Stage 0, no compression and no intraluminal fibrous bands; Stage 1, evidence of compression by surrounding anatomical structures with or without the presence of fibrous bands; Stage 2: evidence of compression with or without fibrous bands as evidenced by cross-pelvic collaterals; Stage 3: compression of the left common iliac vein. Fibrous bands replaced by localised occlusion, with collateralisation and no involvement of adjacent venous segments; Stage 4a: as for Stage 3 but with the addition of thrombotic involvement of adjacent venous segments; Stage 4b: as for Stage 4a but with involvement of distal venous segments, femoral and popliteal. Stages 3, 4a or $4 \mathrm{~b}$ correlated well with clinical presentations of DVT, PE, venous ulceration, vulval or cross-pelvic collaterals, ipsilateral limb swelling and claudication. The presence of varicose veins or recurrent varicose veins was a common finding amongst all groups. Conclusion: Acceptance of this classification system would provide a common terminology to allow more transparent assessment of modalities of treatment for this condition.
\end{abstract}

\section{Keywords}

May Thurner Syndrome, Left Common Iliac Vein Compression, Venous Collaterals, Venous Hypertensive Disease, Cross-Pelvic Collaterals, Varicose Veins 


\section{Introduction}

In 2015, Birn and Vedantham [1] published a review of May-Thurner syndrome and other iliac vein lesions. Their review was remarkable for 2 reasons. The first was that both advanced non-invasive diagnostic testing and invasive testing could not be entirely relied upon to make the diagnosis of iliac vein obstruction clinically. Secondly as a result of this review discussion as to what constituted iliac vein compression was rarely possible because of variation in the diagnosis of obstruction. They concluded their review with the statement "it is hoped that future research will provide improved imaging characteristics of iliac vein lesions to enable discrimination of those whose treatment will produce symptom relief versus less significant abnormalities, as well as better ways to quantify venous obstruction". The purpose of this study is to propose a classification of iliac vein obstructive disease based on multiplanar catheter phlebography and to review how this proposed classification has melded with both clinical findings and treatment in a cohort of 61 patients' identified by this technique to have evidence of iliac vein compression/obstruction. The objective of so doing is to approach future reports of treatment for this condition with a common nomenclature.

\section{Methods}

This study was not a clinical trial, but represents a cumulative clinical experience with respect to left common iliac vein compression syndrome gained over 27 years of treating patients with this condition. No experimental techniques were used. All diagnostic and therapeutic procedures are accepted as standard clinical practice. A significant proportion of patients in this study were coincidently found to have left common iliac vein compression during the performance of endovascular treatment for varicose veins. In all patients, informed consent was obtained before the performance of any diagnostic or theraputic interventions.

\subsection{Definition of Terms}

Compression "the state or act of being compressed. To press or squeeze... a hollow thing reducing its capacity.”

Obstruction "blockage of a bodily cavity or passage".

Collateral "an alternative route for blood when primary vessels are blocked".

Fibrous band/spur like abnormalities identified in the origin of the left common iliac vein (Lciv) thought to be due to damage to the vein wall with resultant fibrous healing. Alternatively some consider these to be a congenital abnormality.

\subsection{Radiological Technique}

Venous access was obtained via puncture of the ipsilateral or contralateral common femoral vein with the patient in the supine position and under local anaesthesia. Alternatively the ipsilateral popliteal vein was punctured under local anaesthetic with ultrasound guidance. The patient was placed in the prone position on the $\mathrm{x}$-ray table and access was obtained via Seldinger technique. A catheter was placed appropriately to view venous segments of interest. For the venous segment between the common femoral vein and the inferior vena cava 15 - $20 \mathrm{mls}$ of contrast agent was used per run and 
often with sustained imaging to identify late filling vessels and collaterals. Imaging in this segment was performed with the patient in sustained end expiration. Imaging of the common femoral vein to inferior vena caval venous segments were obtained in the AP or PA plain and at $30^{\circ}$ oblique projections both to the right and the left.

Patients who were undergoing treatment for varicose veins by radiofrequency ablation of the long saphenous vein or short saphenous vein underwent puncture of these respective superficial veins under local anaesthetic with ultrasound guidance. Catheter placement was achieved via this puncture and views obtained from the ipsilateral or contralateral side depending on the approach required for treatment of the varicose veins.

No patient underwent simultaneous radiofrequency ablation of varicose veins and stenting of the iliac veins. 1 patient with the varicose veins and ulceration required interval stenting of the left common iliac vein after radiofrequency ablation of an incompetent long saphenous vein.

\subsection{Classification}

When patients presented symptomatically, the presentation was classified as acute or chronic. The following factors were considered in constructing a classification system for iliac vein lesions: Compression of the left common iliac vein (not being regarded as synonymous with obstruction) by demonstration in triplanar of views; presence or absence of fibrous bands or spurs; obstruction of the venous outflow of the left leg by the development of cross pelvic collaterals or iliolumbar collaterals (filling of the right common iliac vein from these collaterals or the inferior vena cava was often observed); occlusion of the left common iliac vein by localised thrombosis or left common iliac vein occlusion with adjacent or distant thrombotic architecture within the venous lumen. This classification system is provided in Table 1 and corresponds to the findings in Figure 1 and Figure 2.

The following demographic facts were assessed: Age and sex. Following clinical facts were recorded: Presentation with primary varicose veins, presentation with recurrent

Table 1. Findings on triplanar phlebography.

\begin{tabular}{|c|c|}
\hline STAGE 0 & $\begin{array}{l}\text { No compression } \\
\text { No obstruction } \\
\text { No collateralisation } \\
\text { No fibrous bands/spur }\end{array}$ \\
\hline STAGE 1 & Compression of the left common iliac vein with or without fibrous band \\
\hline STAGE 2 & $\begin{array}{l}\text { Compression of the left common iliac vein with collateralisation, with or without } \\
\text { fibrous band, indicating obstruction }\end{array}$ \\
\hline STAGE 3 & $\begin{array}{l}\text { Compression of the left common iliac vein } \\
\text { Fibrous bands replaced by localised occlusion } \\
\text { With collateralisation } \\
\text { No involvement of adjacent venous segments }\end{array}$ \\
\hline STAGE $4 \mathrm{a}$ & $\begin{array}{l}\text { As for STAGE } 3 \text { but with thrombotic or post-thrombotic involvement of adjacent } \\
\text { venous segments }\end{array}$ \\
\hline STAGE 4b & As for STAGE 4a with involvement of distal venous segments popliteal/femoral. \\
\hline
\end{tabular}




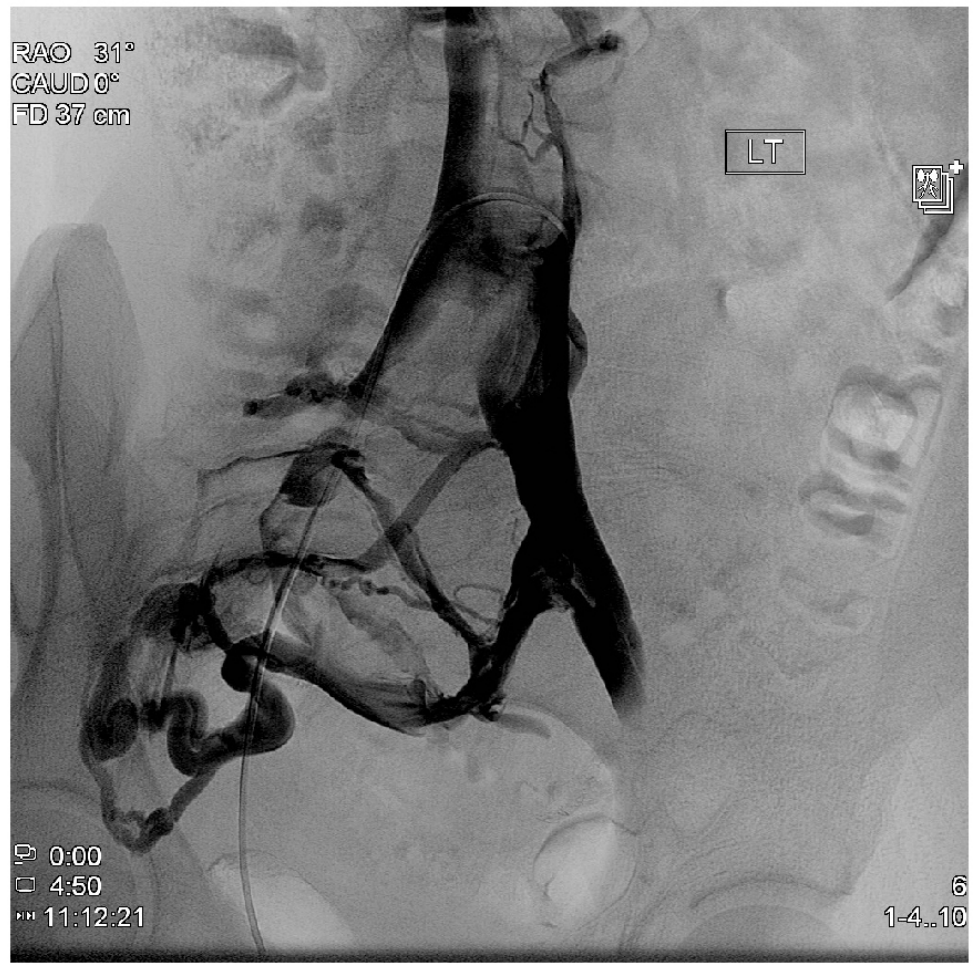

Figure 1. Stage 4a or $4 \mathrm{~b}$ characteristics: Left common iliac vein compression with cross-pelvic collateralization, with collaterals causing early filling of the right common iliac vein and inferior vena cava.

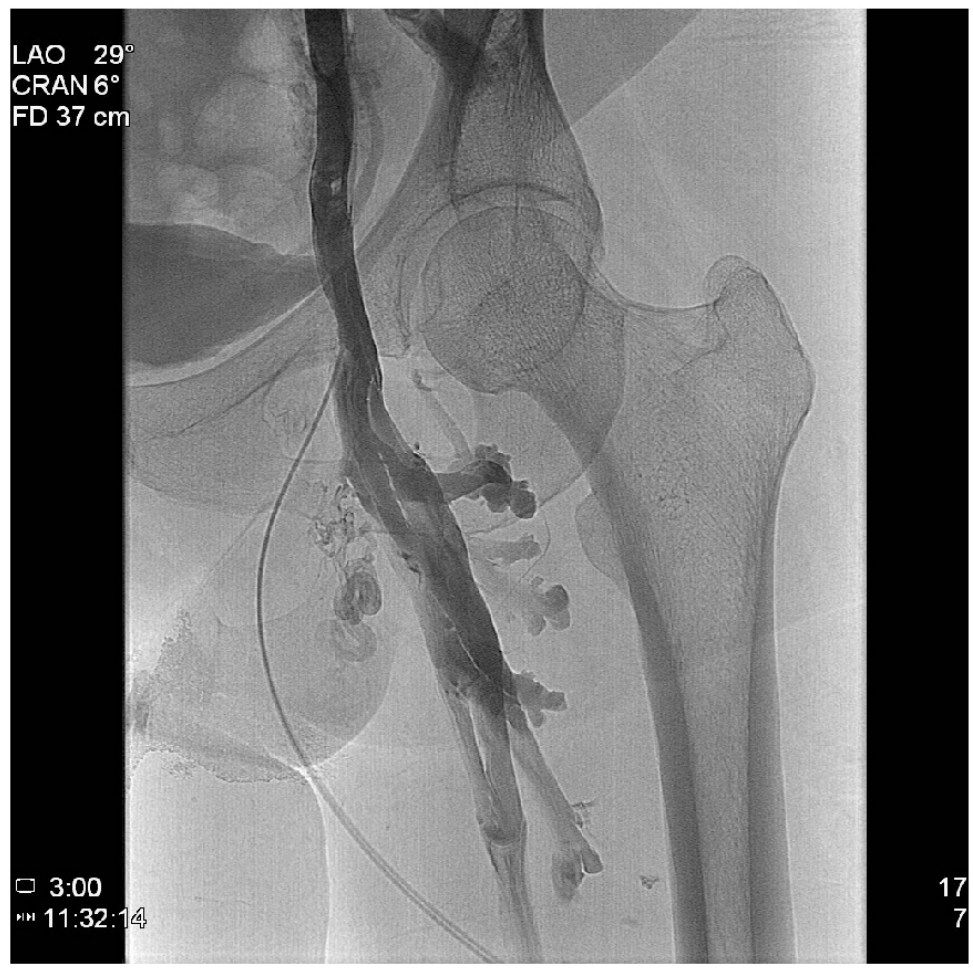

Figure 2. Same patient as Figure 1: Post thrombotic involvement as evidenced by the intraluminalarchitecture involving the external iliac and common femoral veins indicates stage 4 (adjacent or distal involvement of venous segments). This patient also had a popliteal vein occlusion from an odd deep venous thrombosis. 
varicose veins, history of superficial venous thrombosis involving the lower limb, history or presence of DVT involving the ipsilateral lower limb, past or present history of ulceration of the ipsilateral lower limb, presence of vulval or cross pelvic collaterals in the suprapubic region, history or presentation with pulmonary embolus, significant ipsilateral swelling of the lower limb and history or presentation with venous claudication.

The following therapeutic interventions were recorded: Stent placement in the iliofemoral venous segment, use of catheter directed thrombolysis and placement of an inferior vena cava filter in conjunction with this.

Cross tabulation of these factors was performed. Mean age and $95 \%$ confident intervals were calculated.

\section{Results}

Sixty-one consecutive patients consisted of 39 females and 22 males (approximate ratio 2 to 1 ). The mean age of 61 patients was 46 years of age (95\% confidence interval 42 50 years age).

Cross tabulation of stage of left common iliac vein compression/obstruction with symptomatic presentation is provided in Table 2 . In stage I disease varicose veins were the most frequent presentation and the finding of compression of the left common iliac vein was most frequently coincidental and not causally related. There were similar findings in stage II classification probably because the formation of collaterals had adequately decompressed this venous segment. In stage III disease as well as a significant incidence of varicose veins there was also frequent significant swelling and venous claudication symptomatology present. There was also a less frequent presentation with ulceration and venous thromboembolic events.

In stage $4 \mathrm{~A}$ and $4 \mathrm{~B}$ classification, presentation with varicose veins was less frequent but swelling and claudication were very frequent. Vulval and cross-pelvic collateralisation were a frequent presentation and there was a high incidence of venous thromboembolic events.

Table 3 cross-tabulates stage with therapeutic intervention. In stage II, 3 patients of 15 underwent stent placement alone for swelling, claudication, painful vulval varices and recurrent varicose veins. In stage III disease 7 patients underwent stent placement for severe swelling and venous claudication. Similarly all these patients presented with varicose veins that were treated most frequently by radiofrequency ablation.

Table 2. Clinical features according to stage of left common iliac venous disease.

\begin{tabular}{|c|c|c|c|c|c|c|c|c|c|}
\hline Stage & $\begin{array}{l}\text { V.V } \\
(\%)\end{array}$ & $\begin{array}{c}\text { Recurrent V.V. } \\
(\%)\end{array}$ & $\begin{array}{l}\text { SVT } \\
(\%)\end{array}$ & $\begin{array}{l}\text { DVT } \\
(\%)\end{array}$ & $\begin{array}{l}\mathrm{PE} \\
(\%)\end{array}$ & $\begin{array}{c}\text { Ulceration } \\
(\%)\end{array}$ & $\begin{array}{c}\text { Vulval/cross-pelvic } \\
\text { collaterals (\%) }\end{array}$ & $\begin{array}{c}\text { Swelling } \\
(\%)\end{array}$ & $\begin{array}{c}\text { Claudication } \\
(\%)\end{array}$ \\
\hline Stage $1(n=17)$ & 100 & 3 & 3 & 0 & 3 & 3 & 0 & 0 & 0 \\
\hline Stage $2(n=15)$ & 93 & 20 & 20 & 6 & 0 & 0 & 6 & 6 & 6 \\
\hline Stage $3(n=7)$ & 100 & 0 & 14 & 14 & 0 & 14 & 0 & 100 & 71 \\
\hline Stage $4 a(n=14)$ & 7 & 7 & 7 & 93 & 0 & 0 & 28.6 & 85.7 & 93 \\
\hline Stage $4 b(n=8)$ & 25 & 25 & 100 & 100 & 37.5 & 0 & 12.5 & 8 & 100 \\
\hline
\end{tabular}

${ }^{\star}$ V.V. = varicose veins, SVT $=$ Superficial venous thrombosis, DVT $=$ deep vein thrombosis \& $\mathrm{PE}=$ pulmonary embolus. 
Table 3. Types of intervention according to stage.

\begin{tabular}{ccccc}
\hline & Stent & Filter & Thrombolysis & Total \\
\hline STAGE 1 & 0 & 0 & 0 & 17 \\
STAGE 2 & 3 & 0 & 0 & 15 \\
STAGE 3 & 7 & 0 & 0 & 7 \\
STAGE 4a & 10 & 2 & 4 & 14 \\
STAGE 4b & 6 & 1 & 3 & 8 \\
Total & & & & 61 \\
\hline
\end{tabular}

In stage IV disease the most frequent associated clinical feature was swelling, claudication, cross-pelvic collaterals and associated venous thromboembolic events. In $70 \%$ $75 \%$ of patient's stent placement was performed but only those with an acute presentation of venous thromboembolism underwent thrombolysis and less than half of those undergoing thrombolysis required simultaneous inferior vena cava filter placement.

\section{Discussion}

Fibrous band/spur formation of the left common iliac vein has been recognised in reports by Virchow in 1851 [2] but also by McMurrich in 1908 [3] and Ehrich in 1943 [4]. May and Thurner [5] reported on the relationship between compression of the left common iliac vein by the aortic bifurcation or the right common iliac artery anteriorly and the lumbar spine posteriorly and the subsequent development of ilofemoral venous thrombosis. Similarly reports by Cockett in 1965 and 1967 [6] and Negus in 1968 brought this condition to a more widespread attention. During this period therapeutic intervention was limited to anticoagulation alone or the performance of significant surgical intervention [7].

During the 1990s, with the development of stent technology and in combination with catheter directed thrombolysis [8] [9] it became possible to treat this condition percutaneously and under local anaesthetic. With these developments those interventions have become increasingly popular. However a review written in 2016 [10] stated, "the quality of evidence to support the use of the deep venous stenting to treat obstructive chronic venous disease is currently weak. The treatment does however appear promising and is safe and should therefore be considered as a treatment option while the evidence base is improved. The fact that has become increasingly clear is that in contradistinction to the situation with respect to lower limb arterial disease, where agreed classifications with respect to lesion and symptomatology exist, agreed classifications with respect to iliac venous disease does not. CIRSE standards of practice guidelines on iliocaval stenting [11] suggest that a degree of $30 \%$ stenosis or more is appropriate for stenting.

The purpose of this report is not to claim a demonstrated benefit for ileo-caval stenting but rather to suggest a common terminology that reflects the extent and progression of this the disease process, thereby allowing rational comparison between reported interventions. Until an agreed descriptive nomenclature is arrived at with respect to iliocaval disease, little progress is likely to be made with respect to the benefits 
of intervention.

"Catheter phlebography... has often been considered the most definitive available imaging test for the evaluation of obstructive venous pathology" [1]. Catheter phlebography must be performed in multiple projections to clearly identify the "Pan-caked" iliac vein, which is not appreciated in the anteroposterior or posteroanterior projections alone.

The presence of true collateral formation can only be regarded as strong evidence for venous obstruction [12]. However false collaterals may be produced by dependent filling of presacral veins with the patient in the supine position. The state of respiration may also influence pulmonary arterial resistance and thereby result in filling of pelvic veins which do not act as collaterals. True collateral formation can be evidenced by the presence of dilated tortuous veins that fill the right common iliac vein or inferior vena cava before entering the left common iliac vein. Dependent filling of the pelvic venous circulation is less likely to be seen with the patient in the prone position. No other imaging modality is likely to provide the haemodynamic data provided by catheter-based phlebography.

Data with respect to intraluminal venous architecture due to past or present thrombus formation could be provided by other modalities such as IVUS [13] [14] [15],. However it is unlikely that stent placement or other interventions such as catheter directed thrombolysis or inferior vena cava filter placement would be performed in the absence of catheter-based phlebography.

This study proposes a classification of obstructive disease of the iliac venous system that correlates with clinical findings and is a reasonable reflection of both the severity and progression of obstructive disease of the left common iliac vein. Until an appropriate nomenclature is agreed upon little progress is likely to be made with respect to appropriate indications for intervention.

\section{Conclusion}

The purpose of this study was to highlight the difference between left common iliac vein compression and left common iliac vein obstruction using the gold standard of triplanar pelvic phlebography. Based on this clinical experience, a staging classification is offered, which the author believes should it be accepted, would create a clear nomenclature for left common iliac vein pathology. The usage of this classification would make it easier to gain an understanding of appropriate treatment for this condition.

\section{References}

[1] Birn, J. and Vedantham, S. (2015) May-Thurner Syndrome and Other Obstructive Iliac Vein Lesions: Meaning, Myth, and Mystery. Vascular Medicine, 20, 74-83. https://doi.org/10.1177/1358863X14560429

[2] Virchow, R. (1851) Uber die Erweiterung Kleinerer Gefasse. Arch Path. Anat, 3, 4279. https://doi.org/10.1007/BF01960918

[3] Mcmurrich, J.P. (1908) The Occurrence of Congenital Adhesions in the Common Iliac Veins, and Their Relation to Thrombosis of the Femoral and Iliac Veins. The American Journal of the Medical Sciences, 135, 342-345. https://doi.org/10.1097/00000441-190803000-00004 
[4] Ehrich, W.E. and Krumbhaar, E.B. (1943) A Frequent Obstructive Anomaly of the Mouth of the Left Common Iliac Vein. American Heart Journal, 26, 737-750. https://doi.org/10.1016/S0002-8703(43)90285-6

[5] May, R. and Thurner, J. (1957) The Cause of the Predominantly Sinistral Occurrence of Thrombosis of the Pelvic Veins. Angiology, 8, 419-427. https://doi.org/10.1177/000331975700800505

[6] Cockett, F.B., Thomas, M.L. and Negus, D. (1967) Iliac Vein Compression-Its Relation to Iliofemoral Thrombosis and the Post-Thrombotic Syndrome. British Medical Journal, 2, 14. https://doi.org/10.1136/bmj.2.5543.14

[7] Tibbs, D.J. (1992) Varicose Veins and Related Disorders. Butterworth-Heinemann, Oxford, 471.

[8] Semba, C.P. and Dake, M.D. (1994) Iliofemoral Deep Venous Thrombosis: Aggressive Therapy with Catheter-Directed Thrombolysis. Radiology, 191, 487-494. https://doi.org/10.1148/radiology.191.2.8153327

[9] Mewissen, M.W., Seabrook, G.R., Meissner, M.H., Cynamon, J., Labropoulos, N. and Haughton, S.H. (1999) Catheter-Directed Thrombolysis for Lower Extremity Deep Venous Thrombosis: Report of a National Multicenter Registry 1. Radiology, 211, 39-49.

https://doi.org/10.1148/radiology.211.1.r99ap4739

[10] Seager, M.J., Busuttil, A., Dharmarajah, B. and Davies, A.H. (2016) A Systematic Review of Endovenous Stenting in Chronic Venous Disease Secondary to Iliac Vein Obstruction. Journal of Vascular Surgery, 2, 555-556. https://doi.org/10.1016/j.jvs.2015.12.005

[11] Mahnken, A.H., Thomson, K., de Haan, M. and O’Sullivan, G.J. (2014) CIRSE Standards of Practice Guidelines on Iliocaval Stenting. Cardiovascular and Interventional Radiology, 37, 889-897. https://doi.org/10.1007/s00270-014-0875-4

[12] Tibbs, D.J. (1992) Varicose Veins and Related Disorders. Butterworth-Heinemann, Oxford, 157-174.

[13] McLafferty, R.B. (2012) The Role of Intravascular Ultrasound in Venous Thromboembolism. Seminars in Interventional Radiology, 29, 10-15.

[14] Neglén, P. and Raju, S. (2002) Intravascular Ultrasound Scan Evaluation of the Obstructed Vein. Journal of Vascular Surgery, 35, 694-700. https://doi.org/10.1067/mva.2002.121127

[15] Forauer, A.R., Gemmete, J.J., Dasika, N.L., Cho, K.J. and Williams, D.M. (2002) Intravascular Ultrasound in the Diagnosis and Treatment of Iliac Vein Compression (May-Thurner) Syndrome. Journal of Vascular and Interventional Radiology, 13, 523-527. https://doi.org/10.1016/S1051-0443(07)61535-8 
Submit or recommend next manuscript to SCIRP and we will provide best service for you:

Accepting pre-submission inquiries through Email, Facebook, LinkedIn, Twitter, etc. A wide selection of journals (inclusive of 9 subjects, more than 200 journals) Providing 24-hour high-quality service

User-friendly online submission system

Fair and swift peer-review system

Efficient typesetting and proofreading procedure

Display of the result of downloads and visits, as well as the number of cited articles Maximum dissemination of your research work

Submit your manuscript at: http://papersubmission.scirp.org/

Orcontact ss@scirp.org 